This item was submitted to Loughborough's Research Repository by the author.

Items in Figshare are protected by copyright, with all rights reserved, unless otherwise indicated.

\title{
Stirred cell membrane emulsification and factors influencing dispersion drop size and uniformity
}

PLEASE CITE THE PUBLISHED VERSION

http://dx.doi.org/10.1021/ie0611094

PUBLISHER

(c) American Chemical Society

VERSION

AM (Accepted Manuscript)

LICENCE

CC BY-NC-ND 4.0

\section{REPOSITORY RECORD}

Stillwell, Michael T., R.G. Holdich, S.R. Kosvintsev, G. Gasparini, and lain W. Cumming. 2012. "Stirred Cell Membrane Emulsification and Factors Influencing Dispersion Drop Size and Uniformity". figshare. https://hdl.handle.net/2134/9314. 
This item was submitted to Loughborough's Institutional Repository (https://dspace.lboro.ac.uk/) by the author and is made available under the following Creative Commons Licence conditions.

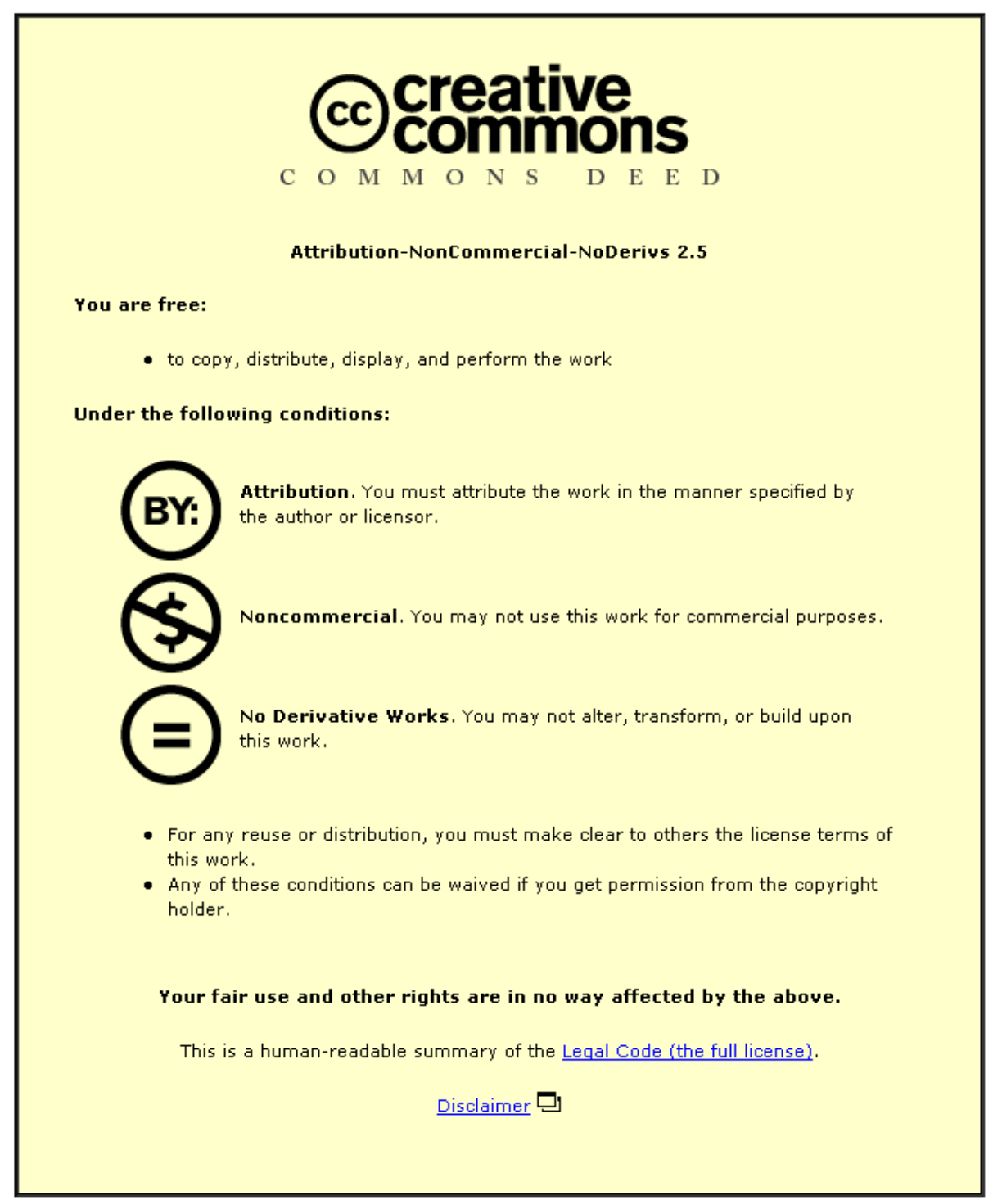

For the full text of this licence, please go to: http://creativecommons.org/licenses/by-nc-nd/2.5/ 


\title{
Stirred Cell Membrane Emulsification and Factors Influencing Dispersion Drop Size and Uniformity
}

\author{
Michael T. Stillwell ${ }^{1}$, Richard G. Holdich ${ }^{1 *}$, Serguei R. Kosvintsev², Gilda Gasparini ${ }^{1}$ \\ and Iain W. Cumming ${ }^{1}$ \\ ${ }^{1}$ Department of Chemical Engineering, Loughborough University, \\ Leicestershire, LE11 3TU, U.K. \\ ${ }^{2}$ Micropore Technologies LTD, Epinal Way, Loughborough, Leics., LE11 3TP.
}

\begin{abstract}
Water-in-oil and oil-in-water emulsions were generated using $30 \mu \mathrm{m}$ pore diameter surface membranes to investigate the factors influencing drop size, and the degree of uniformity of drop size distribution, using a stirred cell employing a simple paddle mounted above a circular disc membrane. The importance of the transitional radius, which is the radius at which the vortex around the unbaffled paddle stirrer changes from a forced vortex to a free vortex and the shear stress at the membrane surface below the stirrer is at its greatest, is demonstrated.
\end{abstract}

Monosized emulsions were produced, with drop size distribution coefficient of variation values of $10 \%$ for $\mathrm{o} / \mathrm{w}$ emulsions and $13.5 \%$ for w/o emulsions. These tests demonstrated that a membrane of reduced annular operating area (ringed membrane) produced a more mono-sized o/w emulsion than a membrane where the full area was used to generate the emulsion, without affecting the mean drop size. The improved size distribution was achieved whilst the transitional radius was located within the ringed annular section of the membrane.

The force balance model, applied to drops formed at the surface of the membrane during emulsification, predicted the droplet diameter provided further drop break up 
within the stirred cell did not occur. Drop break up occurred at Reynolds numbers below 300 for both oil in water and water in oil dispersions. Therefore, for Reynolds numbers greater than this, an annular radial ring membrane can be designed to produce monosized droplets using the stirred cell at known continuous phase viscosities with predictable mean droplet size. This knowledge can be used as a design tool to produce monosized droplets of a specified size for various applications using simple stirred cell emulsification.

keywords

emulsification, sieve-membrane, force balance

*corresponding author's address:

Dr Richard Holdich, Department of Chemical Engineering, Loughborough University, Loughborough, Leicestershire, LE11 3TU, UK. Tel: +44 1509 222519, Fax: +44 1509 223923, e-mail: r.g.holdich@Lboro.ac.uk 


\section{Introduction}

Membrane emulsification is a process to produce an emulsion, or dispersion, of one liquid phase (such as oil) in a second immiscible liquid phase (such as water). The process emerged during the 1990's, starting initially with work performed using porous glass membranes ${ }^{1}$. Initially, the interest was in forming uniformly sized drops at sizes up to 20 microns, for applications such as spacers in electronic displays, calibration particles, etc. There are many reviews covering the early development and applications of the process ${ }^{2,3,4,5}$. More recently, there has been considerable interest in applying the technique of membrane emulsification in the production of liquid drops with much larger diameters than those used initially ${ }^{6}$. These could, after polymerisation or coacervation, have applications in calibration materials, food and flavour encapsulation, controlled release depots under the skin, ion exchange resins, etc $^{7}$. The benefits of membrane emulsification should be more evident in the production of larger (greater than 20 micron) drops as, in general, it is more difficult to control the size and produce a narrow size distribution when working with larger drops. However, the process provides the additional complication of ensuring that the larger drops, once formed, must be kept stable; i.e. without encouraging coalescence, or drop breakage. This is not easily achieved with a crossflow system, hence there is interest in alternative methods of larger diameter droplet production using membrane emulsification ${ }^{6}$.

Dispersions in the size range 2 to 200 microns, with a very narrow drop size distribution, have been reported using what has become known as microfluidics ${ }^{8}$. In this process the dispersing phase can be introduced into the continuous phase through a single capillary, $\mathrm{T}$ junction, or similar device and because of the use of a precise 
flow channel, drops are produced serially from the channel with a very high degree of uniformity. Microfluidics can be extended to produce an array of similar capillaries, etc. which can lead to increased productivity compared to production using a single channel, but scale-up of these techniques to the mass production of uniform drops is still a significant challenge.

Recently, a new membrane type, consisting of an array of uniform pores regularly spaced, has become available. These are analogous to an array of microfluidics capillaries through which the dispersing phase may be introduced into the continuous phase. There are several different types available ${ }^{9,10,11,12,13}$. See Figure 1 for an illustration of this type of membrane, which is the type used in the following study.

In a previous study ${ }^{9}$ a stirred cell was introduced in which membrane emulsification could be achieved using a circular disc membrane of the type illustrated in Figure 1, on top of which a simple paddle blade stirrer induced shear at the membrane surface, resulting in droplet detachment during membrane emulsification. A stirred cell for membrane emulsification is an unusual device to use for a uniform drop distribution, most processes use crossflow or, for the generation of larger diameter drops, microchannels ${ }^{14}$ or a rotating tubular membrane in a stationary liquid ${ }^{6}$. It is commonly believed that a uniform shear field is required for the generation of monosized drops by membrane emulsification, hence devices that provide a uniform shear field at the surface of the membrane are preferred. However, in the previous study it was found that a simple paddle stirrer, with a consequently varying radial shear field at the surface of the membrane, could produce drops of an oil phase dispersed in a low viscosity water phase with a high degree of homogeneity. The membrane pore 
diameter used predominantly in the previous study was $20 \mu \mathrm{m}$ and drops with diameters between 40 and $110 \mu \mathrm{m}$ were produced, the mean size varied as a function of the stirrer speed and, hence, shear imposed at the membrane surface. The present study extends the previous work by considering a membrane with a greater pore size (providing drops up to $200 \mu \mathrm{m}$ ), a consideration of a variety of continuous phase viscosities and both oil-in-water (o/w) as well as water-in-oil (w/o) dispersions. Another critically significant difference between the two studies is the more extensive investigation of the optimum region for droplet generation: in the previous study using a 20 micron pore size membrane there was no significant advantage in restricting the dispersed phase injection zone to a narrow annular ring of membrane operating area. In this study, operating under conditions of a much larger pore size membrane and higher continuous phase viscosities, a significant advantage is apparent.

It was argued in the previous study that at a certain point on the membrane surface, there is a transitional point between the forced and free vortex around the paddle blade stirrer. At this point, the shear stress is greatest, leading to a region where the pressure on the surface of the membrane would be lowest, hence a region which will be more productive in terms of droplets formed through the membrane, as the pressure difference across the membrane will be the greatest at this radius. Hence, mono-sized droplets can be generated from the system because they are predominantly generated from a narrow radial annular region on the disc membrane. Clearly, this conclusion is dependent on the physical properties of the system: continuous phase viscosity, pore size (hence capillary pressure), interfacial tension, etc., as these influence the position of the transitional radius and it is desirable to have 
this radius away from the tip of the stirrer blade to avoid high shear fields and sharp edged surfaces that may damage the newly formed drops.

\section{Dispersed Drop Size Modelling}

The equations used in this study were introduced in the previous work ${ }^{9}$. The preferred model is where the droplet diameter is calculated from a force balance of the capillary force and the drag force acting on a strongly deformed droplet at a single membrane pore

$x=\frac{\sqrt{18 \tau^{2} r_{p}^{2}+2 \sqrt{81 \tau^{4} r_{p}^{4}+4 r_{p}^{2} \tau^{2} \gamma^{2}}}}{3 \tau}$

where $r_{p}$ is the pore radius, $\tau$ is the shear stress, $\gamma$ is the interfacial tension and $x$ is the drop diameter. For the simple paddle-bladed system, as illustrated in Figure 2a, equation 2 can be used to calculate the location of the transitional radius along the paddle blade radius. The transitional radius is the point at which the rotation changes from a forced vortex to a free vortex

$r_{\text {trans }}=\frac{D}{2} 1.23\left(0.57+0.35 \frac{D}{T}\right)\left(\frac{b}{T}\right)^{0.036} n_{b}^{0.116} \frac{\mathrm{Re}}{1000+1.43 \mathrm{Re}}$

where $b$ is the blade height, $T$ is the tank width, $D$ is the stirrer width and $n_{b}$ is the number of blades. The Reynolds Number is defined by $\operatorname{Re}=\frac{\rho w D^{2}}{2 \pi \eta}$, where $\rho$ is the continuous phase density, $\omega$ is the angular velocity and $\eta$ is the continuous phase 
coefficient of dynamic viscosity. In Figure 2a the cell geometry is illustrated. For the experimental equipment used: $H=16 \mathrm{~cm}, D=3.1 \mathrm{~cm}, n_{b}=2$, and $T=3.5 \mathrm{~cm}$.

The boundary layer thickness, $\delta$, is defined by the Landau-Lifshitz ${ }^{15}$ equation

$$
\delta=\sqrt{\frac{\eta}{\rho w}}
$$

The shear stress in the boundary layer above the membrane surface varies according to equations 4 and 5, for radial positions less than the transitional radius and greater than the transitional radius, respectively

$$
\begin{array}{ll}
\tau=0.825 \eta \omega r \frac{1}{\delta} & r<r_{\text {trans }} \\
\tau=0.825 \eta \omega r_{\text {trans }}\left(\frac{r_{\text {trans }}}{r}\right)^{0.6} \frac{1}{\delta} & r>r_{\text {trans }}
\end{array}
$$

In the following modelling work, the maximum shear stress is calculated using equation 4 , or 5 , with $r=r_{\text {trans }}$ for a given rotation speed and continuous phase viscosity. The maximum shear stress is then used in equation 1 to provide the predicted drop size, which is then compared to the experimental values obtained in the following work where shear stresses and continuous phase viscosity were varied. 


\section{Experimental}

Investigations of both w/o and o/w emulsions were performed. For w/o emulsions a 15\% wt/wt solution of poly(vinyl alcohol) (PVA), 98\% hydrolysed, 13000 to 23000 molecular weight supplied by Sigma Aldrich, was dissolved in reverse osmosis water permeate. The continuous phase was low odour kerosene obtained from Sigma Aldrich, containing 0.3\% wt/vol Hypermer B261 and 2\% wt/vol Span 80 surfactants obtained from Uniqema and Fluka respectively. Adding commercially available food grade sunflower oil modified the viscosity of the kerosene continuous phase.

The dispersed phase for the o/w emulsions was paraffin wax obtained from Fluka, catalogue number 76234. The continuous phase was purified water (obtained from a reverse osmosis system) containing 2\% vol/vol Tween 20 surfactant (polysorbate 20) obtained from Sigma Aldrich. The viscosity of the aqueous continuous phase was modified by adding sodium carboxy-methylcellulose (CMC) obtained from Hopkin and Williams Ltd.

Membrane emulsification was performed using a Micropore Technologies Ltd. stirred cell. This device uses a 24 V DC motor to drive a paddle-blade stirrer, which provides the shear at the membrane surface (Figure 2a and 2b). Stirrer speed settings ranging from 2 to $10 \mathrm{~V}$ were used, which are expressed in the results section as their shear stress equivalent values at the transitional radius using equation 4. Membranes with a $30 \mu \mathrm{m}$ pore size were supplied by Micropore Technologies Ltd. (Figure 1). On Figure 2 (c and d), region A indicates pores closed off, region B indicates open pores and region $\mathrm{C}$ indicates the position where the gasket surrounding the membrane inside the stirred cell sits. For the production of all the emulsions a $30 \mu \mathrm{m}$ membrane was used. 
A ringed membrane was also used to produce o/w emulsions. This special membrane has an annular ring of open pores, whereas all of the pores of the standard membrane were open. The dispersed phase was injected through the membrane pores using rates of between 35 to 500 litres of dispersed phase injected per square metre of membrane area per hour $\left(\mathrm{l} \mathrm{m}^{-2} \mathrm{~h}^{-1}\right)$. The continuous phase volume was $150 \mathrm{~cm}^{3}$ and 5 to $10 \mathrm{~cm}^{3}$ of dispersed phase was injected for each experiment.

The number distributions for the w/o and o/w emulsions were obtained using a Horiba laser size analyser (model LA-920) and a Malvern Mastersizer (model S) respectively. Different laser diffraction devices were used because the Malvern employed a water based flow cell, appropriate for the measurement of oil in water emulsions, and the Horiba used a small sample volume cell, appropriate for water in oil emulsions. The uniformity of the number distributions is expressed in terms of the coefficient of variation $(\mathrm{CV})$, which is the relative standard deviation of the particle size distribution. This is a ratio of the standard deviation relative to the mean droplet diameter in percentage terms. The mean value of the number distribution was taken from the statistics provided by the instruments and is used for comparison with the mathematical model.

Interfacial tension measurements were made using the Du Nouy ring method, White Elec. Inst Co Ltd model DB2KS, and tests were performed to check that the viscosity modifying agents did not influence the interfacial tensions significantly. This is important if only the effect of viscosity on drop size, and distribution, is to be investigated. The addition of CMC to the continuous phase had no influence on the interfacial tension between the dispersed phase and the continuous phase. This was 
measured to be an average of 7.0 dynes $\mathrm{cm}^{-1}$ for $0 \%, 1 \%$ and $2.5 \%$ CMC continuous phase content. Likewise, for the addition of sunflower oil to kerosene, the average interfacial tension was found to be insensitive to thickening agent concentration at a value of 4.0 dynes $\mathrm{cm}^{-1}$.

In this study, the influence of increasing the continuous phase viscosity on the emulsion size distribution was investigated for w/o and o/w systems and other factors that may influence the degree of uniformity of the resulting dispersion. Experimental results were compared to the mathematical model used to predict droplet diameter within the stirred cell. The membrane geometry was also investigated regarding the transitional point between a forced and a free vortex in the continuous phase in the simple paddle-blade stirred cell. As a further test of the stirred cell model some work on the influence of shear rate (stirrer speed) and dispersed phase injection rate were also performed.

\section{Results \& Discussion}

\section{W/O Emulsions}

A 15\% wt/wt solution of PVA was injected into a kerosene solution continuous phase containing dissolved surfactants. The continuous phase viscosity was modified by adding sunflower oil. All tests were performed at a constant stirrer speed setting equivalent to a shear stress of 70 dynes $\mathrm{cm}^{-2}$ at the transitional radius. A $30 \mu \mathrm{m}$ pore size standard membrane with a hydrophobic surface coating was used. The mixture of surfactants provided a background haze of very finely divided water drops, which were traced to the presence of the Span 80 surfactant. Hypermer B261 by itself was not found to be adequate to stabilise the drops, so the Span was required, but the 
background matrix of 'Span haze' influenced the laser diffraction readings slightly. There were also difficulties in completely removing gas bubbles from the small sample cell. Hence, CV values greater than those expected by visual observation using a microscope were reported. This was checked by comparing the CV's obtained by the instrumental technique against an image analysis size distribution, using ImageJ software. An example of such an analysis is shown in Figure 3, which was obtained using an injection rate of $210 \mathrm{l} \mathrm{m}^{-2} \mathrm{~h}^{-1}$ of PVA solution into a mixture of $60 \%$ kerosene, $40 \%$ sunflower oil; and shows an example of the original image and the pixelated version of the image for use by the ImageJ software.

The reported CV by the instrumental technique was $25 \%$, whereas the CV by image analysis was $13.5 \%$. This is a typical result and in most cases the CV by image analysis was found to be roughly one half of that by the laser diffraction when analysing w/o emulsions. For the sake of simplicity and consistency, in all the following work the reported CV's will be those obtained by the instrumental technique, but it should be remembered that they are influenced by these effects and CV's by image analysis would be significantly lower.

Table 1 shows how the viscosity of the kerosene continuous phase is affected by the addition of sunflower oil and Figure 4 shows the mean droplet diameter and CV data for the w/o emulsions for continuous phase sunflower oil contents of $0 \%, 40 \%, 60 \%$ and $80 \%$. For these tests the dispersed phase injection rate of $70 \mathrm{l} \mathrm{m}^{-2} \mathrm{~h}^{-1}$ was used. The mean droplet diameter decreased from $77-70 \mu \mathrm{m}$ by adding up to $40 \%$ sunflower oil. This represents a continuous phase viscosity increase from an approximate $1.4 \mathrm{cP}$ (0\% sunflower oil) to $14 \mathrm{cP}$ (40\% sunflower oil). Within this viscosity range, the $\mathrm{CV}$ 
is slightly improved, because the chances of coalescence at the membrane surface are reduced by the increased viscous forces ${ }^{12}$. Further viscosity increases up to $21 \mathrm{cP}$ and $37 \mathrm{cP}$ (60\% and $80 \%$ sunflower oil respectively) reduced the drop diameter even further. However, the CV value increased to a very high level at $80 \%$ sunflower oil. This was caused by severe droplet break-up, which produced a skewed size distribution towards the smaller drop sizes. Droplet diameters less than $30 \mu \mathrm{m}$ were produced at $80 \%$ sunflower oil content, which is smaller than the pore size of the membrane and is attributed to drop break-up in the paddle blade system. The resulting emulsions for all the shears are illustrated in Figure 5.

The model described by equation 1 is included in Figure 4, for the sunflower oil concentrations where drop breakup does not appear to be significant. The predicted diameters are based on the assumption that the bulk of the drops are produced at the transitional radius, which is used in equation 1 to determine the shear. The model appears to slightly underestimate the drop size produced, but it should be apparent that it provides a reasonable fit to the data taking into account the variation in continuous phase viscosity.

The data illustrated in Figures 4 and 5 suggest that increasing the viscosity did have a very small influence on improving the degree of monodispersity of the emulsion, i.e. reduction in the $\mathrm{CV}$, but only up to a value of $14 \mathrm{cP}$. Beyond this, the viscosity became sufficiently high that drop breakup was induced by the paddle stirrer and the improvement in $\mathrm{CV}$ was lost. By comparison, the system using a rotating tubular membrane ${ }^{6}$ did not appear to suffer from this effect. An increasing apparent viscosity led to an increasing degree of monodispersity over the range of $340-800 \mathrm{cP}$ at a fixed 
rotation speed of $350 \mathrm{rpm}$. A further increase in rotation speed up to $1500 \mathrm{rpm}$ did result in droplet break-up, indicating that a careful balance of the shear forces within the system must be achieved.

The mean drop size was influenced by the dispersed phase injection rate, using data from tests on a $40 \%$ sunflower oil content continuous phase. Injection rates of 70 , 210, $420 \mathrm{l} \mathrm{m}^{-2} \mathrm{~h}^{-1}$ produced sizes of 70,84 and $110 \mu \mathrm{m}$ respectively. This is an expected trend as more material is being injected per unit time to each pore, resulting in larger drops before snap-off from the membrane surface. However, the mathematical model (equation 1) does not account for injection rate dependency. The CV remained constant at about 25\% up to an injection rate of $210 \mathrm{l} \mathrm{m}^{-2} \mathrm{~h}^{-1}$, but then increased to $35 \%$ at the highest injection rate. At higher injection rates there is an increased chance of non-uniform size distributions due to unstable large droplets and also droplet break-up.

\section{O/W Emulsions}

Paraffin wax was injected into an aqueous continuous phase containing $2 \% \mathrm{vol} / \mathrm{vol}$ Tween 20 surfactant. The initial tests were performed using a $30 \mu \mathrm{m}$ pore size hydrophilic standard membrane and ringed membrane (with reduced active area for dispersed phase injection). Figure 6 compares the emulsions generated using the standard membrane and the ringed membrane at the same operating conditions and includes the results from the model, equation 1.

From Figure 6 there appears to be little advantage from using the ringed membrane: the mean drop sizes are similar and the agreement with equation 1 is very good. It is 
noticeable that the agreement is slightly better for the ringed membrane over most of the shear stresses. However, the data illustrated in Figure 7 shows that the ringed membrane has a considerable advantage over the standard membrane if the degree of uniformity of the drops is important: the CV values for the ringed membrane are roughly one half (approximately 12\%) of that of the standard membrane, for all shear conditions apart from the lowest shear stress.

The emulsions produced under these shear conditions, using the ringed membrane, are illustrated in Figure 8.

The reason for the lower $\mathrm{CV}$ is that according to equation 2 the transitional radius occurred between 1.06 to $1.18 \mathrm{~cm}$ from the centre of the membrane, which is within or very close to the open ring portion of the membrane $(0.8$ to $1.1 \mathrm{~cm})$. At this point, the shear stress in the boundary layer is at a maximum value and the shear stress with radial position will be more consistent at this radius than over other radii, where the shear is continually increasing, or decreasing, with radial position. Thus, a more mono-sized emulsion will result. Previous work concluded that having rings of open and closed membrane pores, for a pore diameter of $20 \mu \mathrm{m}$, had little affect on the emulsion size distribution ${ }^{9}$. However, for a larger pore diameter $(30 \mu \mathrm{m})$ the capillary pressure will be very significantly less and it is likely that the system will be more sensitive. The ringed membrane provided a significant advantage over the standard membrane and, therefore, only the ringed hydrophilic membrane was used for the rest of the o/w experiments. In the mathematical analysis, the shear used in equation 1 was the shear at the transitional radius when that radius falls within the ringed membrane region, but when the transitional radius falls outside of the ringed region the shear 
according to equations 4 , or 5 , was used with an average radial position within the ringed region used in the equations.

Figure 9 shows the influence of increasing the injection rate of the dispersed phase on the droplet size distribution for a 0\% CMC continuous phase content and a shear stress of 68 dyne $\mathrm{cm}^{-2}$ using the ringed membrane. The mean droplet diameter increased slightly from 86 to $95 \mu \mathrm{m}$ for an increased injection rate between 84 to 3351 $\mathrm{m}^{-2} \mathrm{~h}^{-1}$. The mean droplet diameter then decreased to $92 \mu \mathrm{m}$ with a further injection rate increase to $503 \mathrm{l} \mathrm{m}^{-2} \mathrm{~h}^{-1}$.

There has been work previously published considering the influence of injection rate on drop size ${ }^{\mathbf{1 0}}$. In that work, a "push-to-detach” droplet formation mechanism was postulated: when a critical injection rate is exceeded, all of the membrane pores become active and droplet formation at one pore is affected by the presence of other droplets forming at adjacent pores. This causes the droplets to detach sooner, producing smaller diameter and more uniform droplets. However, for the data illustrated in Figure 9, the CV consistently increased from $10 \%$ to $17 \%$ as the injection rate increased. Also, the drop size increases with injection rate, until the highest injection rate. Hence, it is reasonable to conclude that in the case of the data illustrated in Figure 9, the increase in drop size with injection rate is not influenced by the pore density of the membrane, but is due to some form of dynamic effect within the process. At the highest injection rate drop breakage is apparent.

Figure 10 shows an image of the drops produced at the injection rate of $503 \mathrm{l} \mathrm{m}^{-2} \mathrm{~h}^{-1}$, which can be compared with the image shown in Figure 8 at an injection rate of $168 \mathrm{l}$ 
$\mathrm{m}^{-2} \mathrm{~h}^{-1}$. Both were performed at a shear stress of 68 dynes $\mathrm{cm}^{-2}$, and all other conditions were maintained constant. Visually, at the higher injection rate there appears to be a higher proportion of larger drops, but the smallest size drops (approximately 80 to $90 \mu \mathrm{m}$ ) appear to be the same in both figures. Images from these emulsions were analysed using ImageJ software and the resulting distribution is shown in Figure 11.

At the higher injection rate there appears to be some small material, sub $60 \mu \mathrm{m}$, produced probably by drop break up. Neglecting the sub $60 \mu \mathrm{m}$ material, the two distributions start at the same size range: 80 to $85 \mu \mathrm{m}$, but at the higher injection rate there is a significant amount of larger material generated: up to $145 \mu \mathrm{m}$. Thus, increasing the injection rate did not appear to alter the size of the smallest material generated, but broadens the distribution by creating some larger drops.

The viscosity of the water/Tween 20 continuous phase was modified by adding CMC, see Table 2 for the resulting coefficients of dynamic viscosity. Dispersions were made with $1.0 \%$ and $2.5 \%$ CMC concentrations at shear stress values of 78.0 and 8.0 dynes $\mathrm{cm}^{-2}$ respectively at the centre of the annular radius $(\mathrm{r}=0.95 \mathrm{~cm})$. The paraffin wax was injected at rates of $168 \mathrm{l} \mathrm{m}^{-2} \mathrm{~h}^{-1}$ and $335 \mathrm{l} \mathrm{m}^{-2} \mathrm{~h}^{-1}$ at both viscosities. The resulting mean droplet size and CV are compared to the model (equation 1) in Figure 12. In Figure 12 the spread of the CV data shows the minimum CV value is obtained from the $168 \mathrm{l} \mathrm{m}^{-2} \mathrm{~h}^{-1}$ injection rate, and the maximum CV from the $503 \mathrm{l} \mathrm{m}^{-2} \mathrm{~h}^{-1}$ injection rate. 
Equation 1 provides a good fit to the data at $\% \%$ CMC and at 1\% CMC concentration. However, the drop size distribution is particularly wide, with a CV of about $50 \%$. At a CMC concentration of $2.5 \%$ it appears that very significant drop breakage has occurred, with a mean size of about $30 \mu \mathrm{m}$ and a CV approaching $100 \%$. The model appears to be able to predict the drop size as a function of shear where that is due to rotation speed, or viscosity, provided that drop breakage is not significant.

For the w/o and o/w emulsions, the position of the transitional radius decreases towards the centre of the stirred cell as the continuous phase viscosity increases, for a constant stirrer speed. A decrease in the radius from $1.11 \mathrm{~cm}$ to $0.24 \mathrm{~cm}$ is shown for the w/o emulsion as the sunflower oil content is increased from $0 \%$ to $100 \%$. A decrease in the transitional radius from $1.16 \mathrm{~cm}$ to $0.05 \mathrm{~cm}$ occurs for the $\mathrm{o} / \mathrm{w}$ emulsion as the CMC content is increased from $0 \%$ to $2.5 \%$.

The inner and outer radii of the ringed section of the membrane are $0.8 \mathrm{~cm}$ and $1.1 \mathrm{~cm}$ respectively (Figure 2d). The $0 \%$ CMC continuous phase content provides a transitional radius of $1.16 \mathrm{~cm}$, which is within the range of the open pores inside the ringed section of the membrane at the shear stress used in this study. By increasing the shear stress at the membrane surface, by an increase in stirring rate, the transitional radius can be brought further within the ring to produce potentially more mono-sized emulsions for the 0\% CMC continuous phase content. As the continuous phase viscosity is increased, the location of the transitional radius changes significantly. The $1 \%$ and $2.5 \%$ CMC solutions have transitional radii of $0.38 \mathrm{~cm}$ and $0.05 \mathrm{~cm}$ respectively, which are well outside of the range of the open pores inside the ring. It appears that when using a stirred cell system, if a high degree of drop 
uniformity is required, then a ringed membrane is an advantage provided that the transitional radius is within the ringed annular radial area. The effect is more pronounced with membranes having a larger pore size, compared to the previous study ${ }^{9}$.

The Reynolds numbers were calculated for the shear conditions when drop breakup was observed for both the o/w and the w/o emulsions. It was found that for Reynolds numbers less than 300 very significant drop breakup occurred; resulting in mean drop sizes below that of the membrane pore size. Hence, this is attributed to drop breakup in the stirred system rather than due to generation at the membrane pore surface. At higher Reynolds numbers more uniform drop size distributions were observed. Thus, the drop breakup is not attributed to turbulent effects, but is related to high viscous shear forces within the cell.

\section{Conclusions}

Water-in-oil and oil-in-water emulsions were generated using $30 \mu \mathrm{m}$ pore size surface membranes to investigate the factors influencing drop size and the degree of uniformity of drop size distribution. The importance of the transitional radius, which is the radius at which the vortex around the stirrer changes from a forced vortex to a free vortex and the shear stress at the membrane surface below the stirrer is at its greatest, is demonstrated.

Monosized emulsions were produced at low continuous phase viscosities, with CV values of $10 \%$ for o/w emulsions and $13.5 \%$ for w/o emulsions using optical analysis for the latter. These tests also demonstrated that a membrane of reduced radial 
operating area (ringed membrane) produced a more mono-sized o/w emulsion than the standard membrane (the CV reduced from 25\% down to $10 \%$ using the ringed membrane). However, the mean drop size was not influenced by the use of a ringed membrane, or otherwise. The better size distribution appeared to be connected to the location of the transitional radius. When the operating region of the ringed membrane contained the transitional radius the drop size distribution uniformity was good. However, when the transitional radius was at a significant distance from the ringed operating area the drop size distribution was poor.

The force balance model predicts very well the droplet diameter produced for emulsions at low to medium viscosity continuous phases, provided the transitional radius is within the ring. Therefore, for a projected design or new system, once the continuous phase viscosity has been determined, the transitional radius can be calculated from equation 2. An annular radial ring membrane can then be designed to produce monosized droplets using the stirred cell. Further, the model can be used to predict the mean droplet size. This knowledge can be used as a design tool to manufacture monosized droplets of a specified size for various applications.

The CV and droplet size were slightly dependent upon the dispersed phase injection rate, however, the mathematical model does not incorporate the dispersed phase injection rate as a parameter. In all cases the drop size increases slightly as a function of injection rate, until the point at which drop breakup is reached. The CV is also dependent upon the continuous phase viscosity. A limited reduction in droplet size CV can be achieved by an increase in viscosity, but large viscosities lead to droplet break-up in the high viscous shear forces within the stirred system. To avoid drop 
breakup a Reynolds number of above 300 was required, for both the o/w and the w/o systems. 


\section{REFERENCES}

(1) Mine, Y. Shimizu, M., Nakashima, T., Preparation and stabilisation of simple and multiple emulsions using a microporous glass membrane, Colloids and Surfaces B, 1996, 6, 261.

(2) Vladisavljevic, G.T. and Williams, R.A., Recent developments in manufacturing emulsions and particlulate products using membranes, Adv. Coll. \& Int. Sci., 2005, 113, 1.

(3) Joscelyne, S.M. and Tragardh, G., Membrane emulsification - a literature review, Jnl. Mem. Sci., 2000, 169, 107.

(4) Abrahamse, A.J.G., van der Padt, A., Boom, R.M., Status of cross-flow membrane emulsification and outlook for industrial application, Journal of Membrane Science, 2004, 230, 149.

(5) Williams, R.A., Peng, S.J., Wheeler, D.A., Morley, N.C., Taylor, D., Whalley, M. and Houldsworth, D.W., Controlled production of emulsions using a crossflow membrane Part II: industrial scale manufacture, Trans. IChemE., 1998, 76, 902.

(6) Vladisavljevic, G.T. and Williams, R.A., Manufacture of large uniform droplets using rotating membrane emulsification, Journal of Colloid and Interface Science, 2006, 299, 396.

(7) Nakashima, T, Shimizu, M., Kukizaki, M., Particle control of emulsion by membrane emulsification and its applications, Advanced Drug Delivery Reviews, 2000, 45, 47.

(8) Umbanhowar, P. B., Prasad, V. and Weitz, D. A., Monodisperse Emulsion Generation via Drop Break Off in a Coflowing Stream, Langmuir 2000, 16, 347. 
(9) Kosvintsev, S.R., Gasparini, G., Holdich, R.G., Cumming, I.W., and Stillwell, M.T., Liquid-liquid membrane dispersion in a stirred cell with and without controlled shear, Ind Eng Chem Res, 2005, 44, 9323.

(10) Zhu, J. and Barrow, D., Analysis of droplet size during cross-flow membrane emulsification using stationary and vibrating micromachined silicon nitride membranes, Journal of Membrane Science, 2005, 261, 136.

(11) Dowding, P.J., Goodwin, J.W., Vincent, B., Production of porous suspension polymer beads with a narrow size distribution using a cross-flow membrane and a continuous tubular reactor, Colloids and Surfaces A, 2001, 180, 301.

(12) Vladisavljevic, G.T., Tesch, S., Schubert, H., Preparation of water-inoil emulsions using microporous polypropylene hollow fibres; influence of some operating parameters on droplet size distribution, Chemical Engineering and Processing, 2002, 41, 231.

(13) Schadler, V. and Winhab, E.J., Continuous membrane emulsification by using a membrane system with controlled pore distance, Desalination, 2006, 189, 130.

(14) Sugiura, S. Nakajima, M. and Seki, M., Preparation of monodispersed polymeric microspheres over $50 \mu \mathrm{m}$ employing microchannel emulsification, Ind. Eng. Chem. Res., 2002, 41, 4043.

(15) Landau, L.D. and Lifshitz, E.M., Fluid Mechanics, 1959, Pergamon Press, Oxford, UK. 


\section{List of Tables}

Table 1 Coefficient of dynamic viscosity for mixtures of kerosene and sunflower oil

Table 2 Continuous phase viscosity as carboxy methyl cellulose (CMC) is added to water 
List of Figures

Figure 1 Regular array of pores on membrane used to produce emulsions

Figure 2 Schematic of stirred cell showing shear profile (b), standard membrane area (c) operating for dispersion and an annular radial ring (d)

membrane for dispersion

Figure 3 Image obtained under a microscope of the w/o emulsion produced using a $40 \%$ sunflower oil content in kerosene mixture continuous phase and a $210 \mathrm{l} \mathrm{m}^{-2} \mathrm{~h}^{-1}$ injection rate of PVA aqueous solution and pixelated version for image analysis by ImageJ software

Figure 4 Droplet diameter and CV variation as a function of sunflower oil content for w/o emulsions at shear stresses of 70, 126, 127 and 120 dynes $\mathrm{cm}^{-2}$ for 0 , 40, 60 and $80 \%$ sunflower oil contents respectively, with predicted sizes from equation 1 until drop break-up predominates

Figure 5 w/o emulsion droplets produced in continuous phases with sunflower oil contents of (a) $0 \%$ (b) $40 \%$ (c) $60 \%$ and (d) $80 \%$ at a $70 \mathrm{l} \mathrm{m}^{-2} \mathrm{~h}^{-1}$ injection rate and shear stresses of 70, 126, 127 and 120 dynes $\mathrm{cm}^{-2}$ respectively

Figure 6 Comparison of $\mathrm{o} / \mathrm{w}$ emulsion data produced using the ringed membrane and the standard membrane with a continuous phase viscosity of $1 \mathrm{cP}$ including predicted values from equation 1

Figure 7 Comparison of $\mathrm{CV}$ values from o/w emulsion data produced using the ringed membrane and the standard membrane with a continuous phase viscosity of $1 \mathrm{cP}$ 
Figure 8 o/w emulsion images for the ringed membrane at an injection rate of $168 \mathrm{l} \mathrm{m}^{-2} \mathrm{~h}^{-1}$ and a $0 \%$ continuous phase CMC content at different membrane shear stresses

Figure 9 Droplet diameter and CV variation for the O/W emulsion as a function of dispersed phase injection rate: $0 \%$ CMC content and a shear rate of 68 dynes $\mathrm{cm}^{-2}$

Figure 10 Image of o/w emulsion image for the ringed membrane at an injection rate of $503 \mathrm{l} \mathrm{m}^{-2} \mathrm{~h}^{-1}$ and a $0 \%$ continuous phase CMC content at a membrane shear stress of 68 dynes $\mathrm{cm}^{-2}$

Figure 11 ImageJ analysis of images at 168 and $503 \mathrm{l} \mathrm{m}^{-2} \mathrm{~h}^{-1}$ dispersed phase injection rate at $0 \%$ continuous phase CMC content at a membrane shear stress of 68 dynes $\mathrm{cm}^{-2}$

Figure 12 Comparison of predicted droplet diameter and the measured mean droplet diameter for the o/w emulsion at 168 and $335 \mathrm{l} \mathrm{m}^{-2} \mathrm{~h}^{-1}$ injection rate at the radial position of the ring under a constant shear stresses of 78.0 and 7.0 dynes $\mathrm{cm}^{-2}$ for $1 \%$ and $2.5 \%$ CMC content in the continuous phase 
Table 1 Coefficient of dynamic viscosity for mixtures of kerosene and sunflower oil

\begin{tabular}{|l|c|c|c|c|c|c|c|c|}
\hline Sunflower oil proportion in kerosene (\%) & 0 & 40 & 50 & 60 & 70 & 80 & 90 & 100 \\
\hline Coefficient of dynamic viscosity (cP) & 1.4 & 14 & 16 & 21 & 29 & 37 & 57 & 64 \\
\hline
\end{tabular}


Table 2 Continuous phase viscosity as carboxy methyl cellulose is added to water

\begin{tabular}{|l|c|c|c|c|c|}
\hline Proportion of CMC (\%) & 0 & 1.0 & 2.5 & 4.0 & 5.0 \\
\hline Coefficient of dynamic viscosity (cP) & 1 & 38 & 310 & 400 & 487 \\
\hline
\end{tabular}




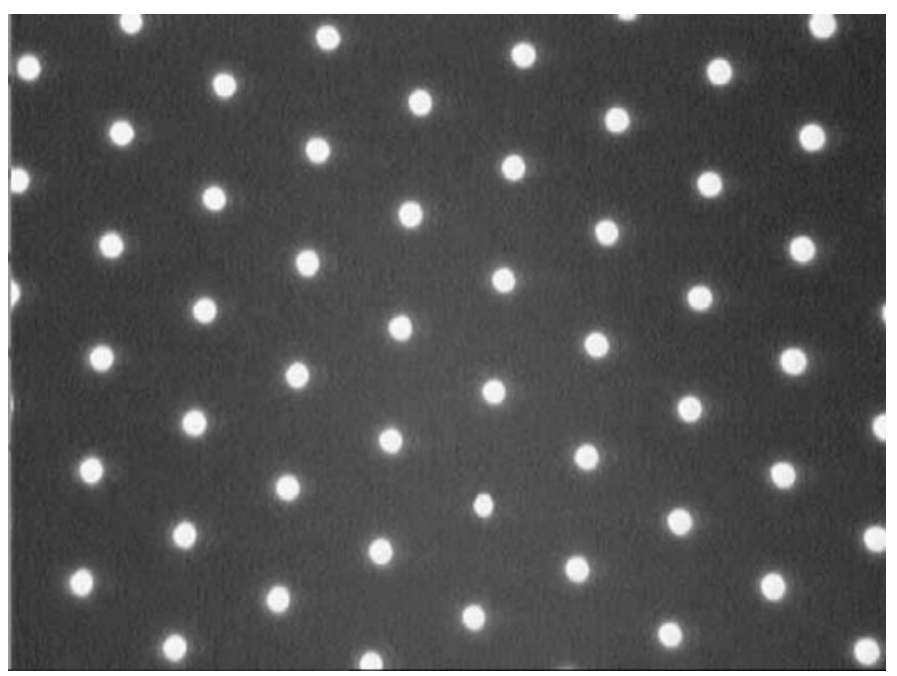

Figure 1 Regular array of pores on membrane used to produce emulsions 
a)

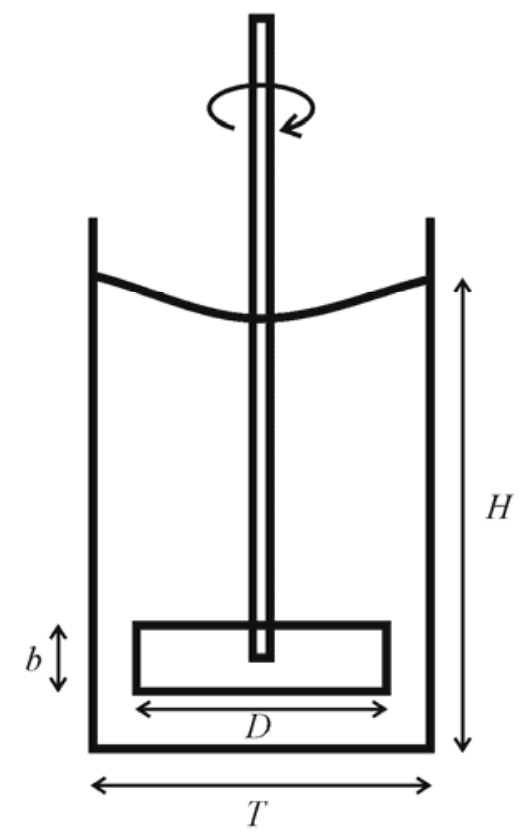

c)

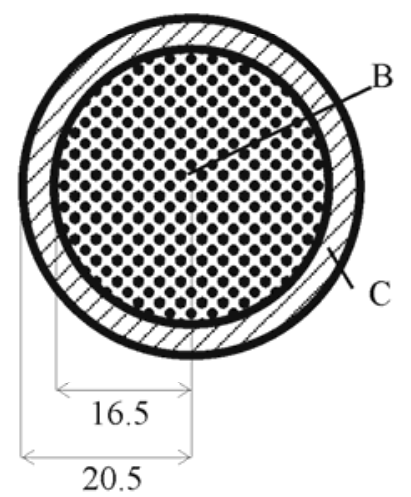

b)

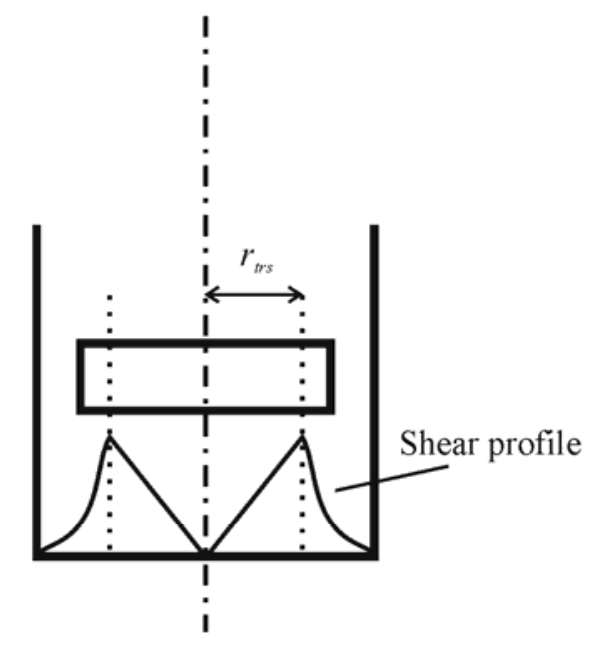

d)

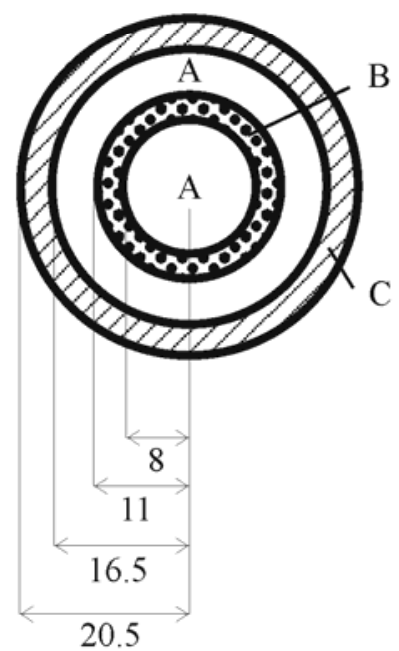

Figure 2 Schematic of stirred cell showing shear profile (b), standard membrane area (c) operating for dispersion and an annular radial ring (d) membrane for dispersion 

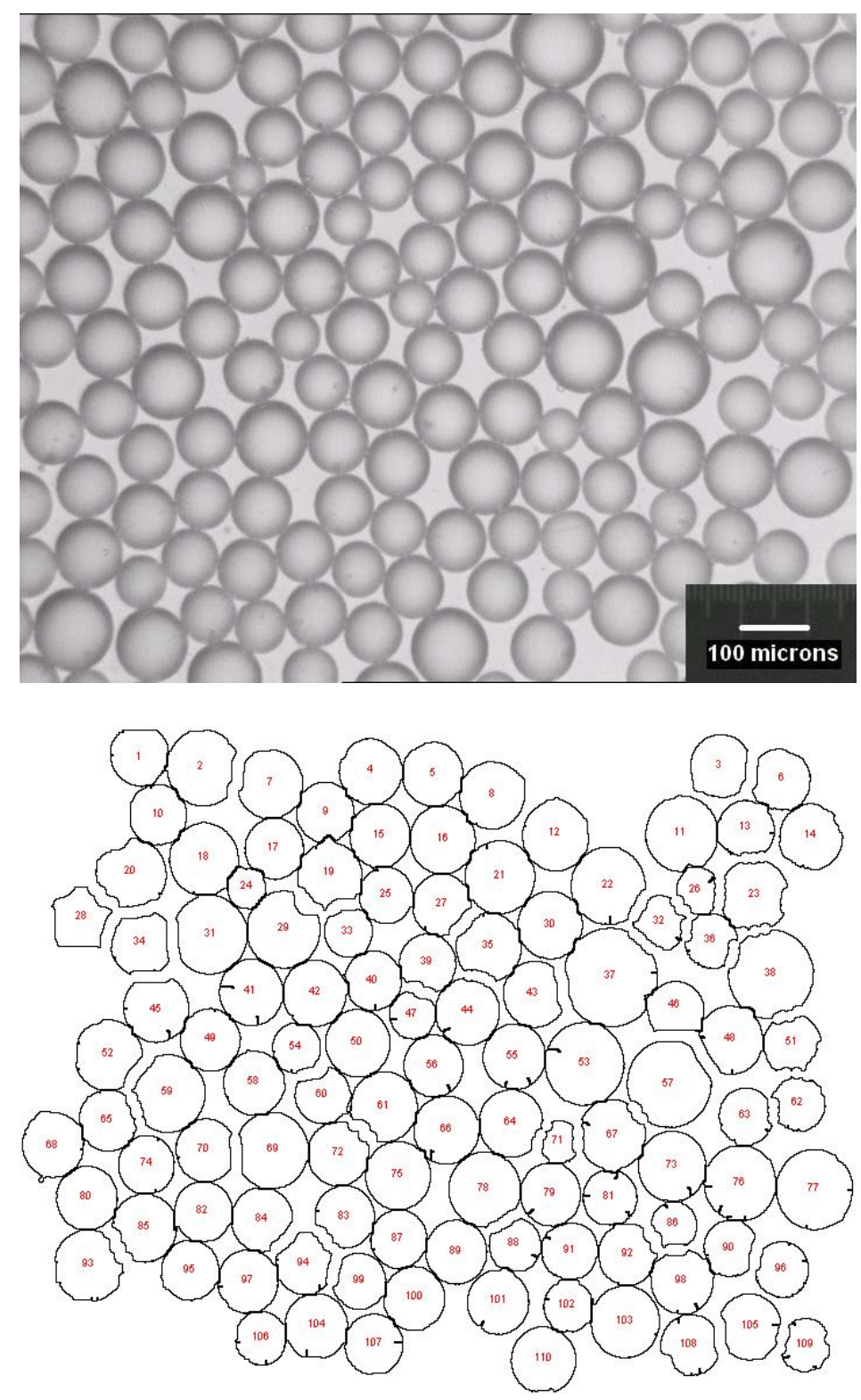

Figure 3 Image obtained under a microscope of the w/o emulsion produced using a $40 \%$ sunflower oil content in kerosene mixture continuous phase and a $210 \mathrm{l} \mathrm{m}^{-2} \mathrm{~h}^{-1}$ injection rate of PVA aqueous solution and pixelated version for image analysis by ImageJ software 


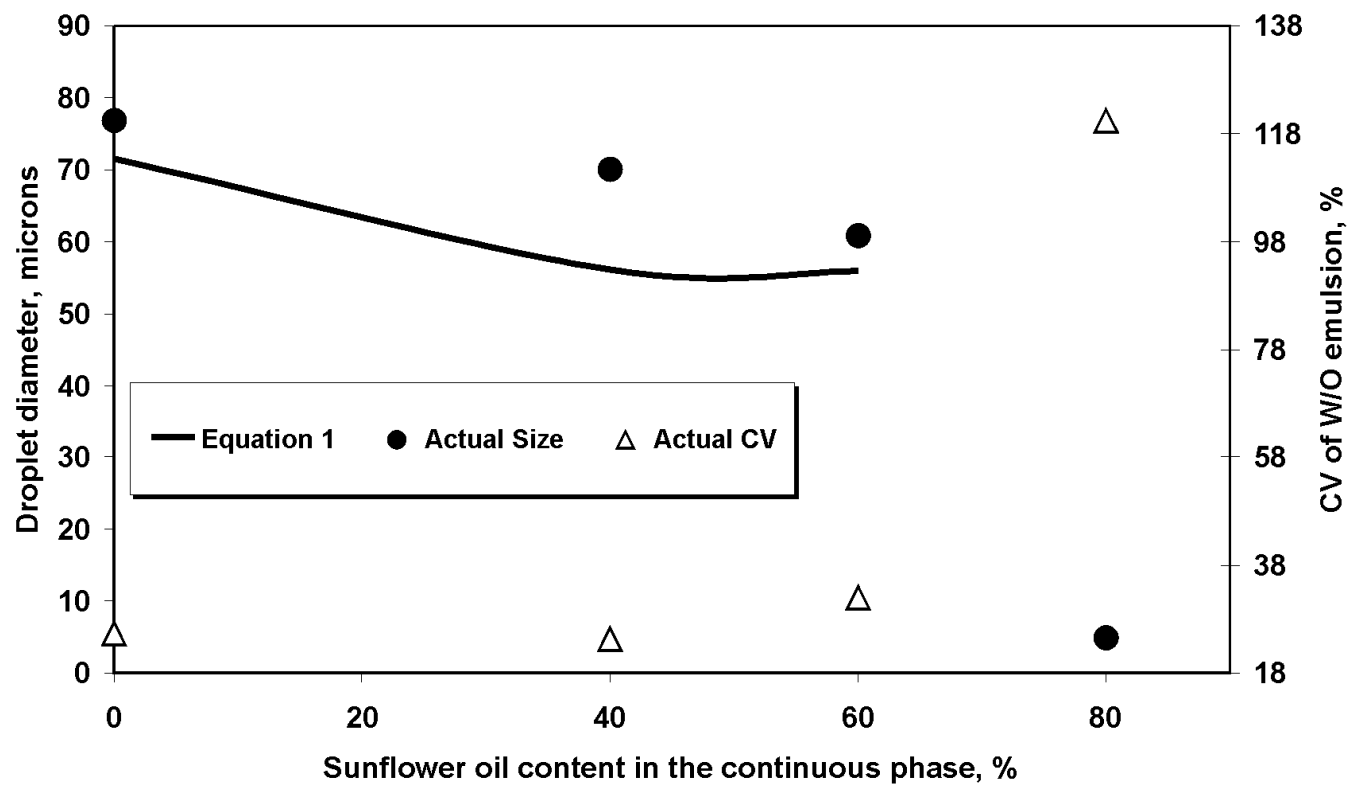

Figure 4 Droplet diameter and CV variation as a function of sunflower oil content for w/o emulsions at shear stresses of 70, 126, 127 and 120 dynes $\mathrm{cm}^{-2}$ for $0,40,60$ and $80 \%$ sunflower oil contents respectively, with predicted sizes from equation 1 until drop break-up predominates 
a

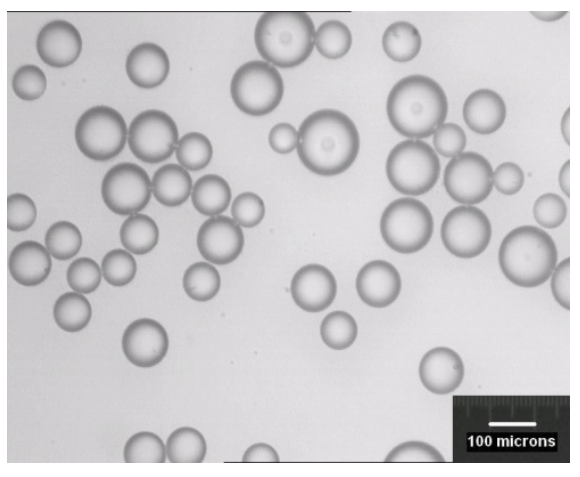

c

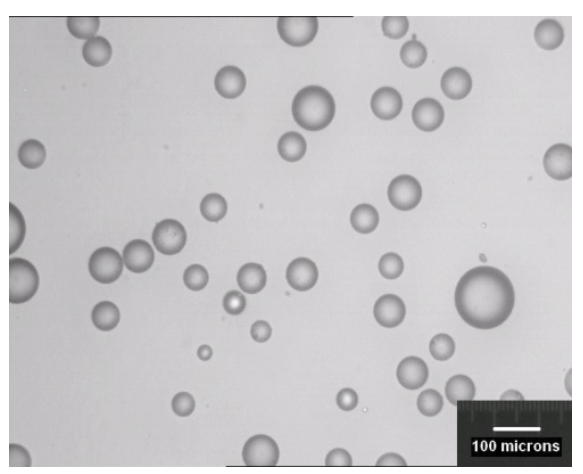

b

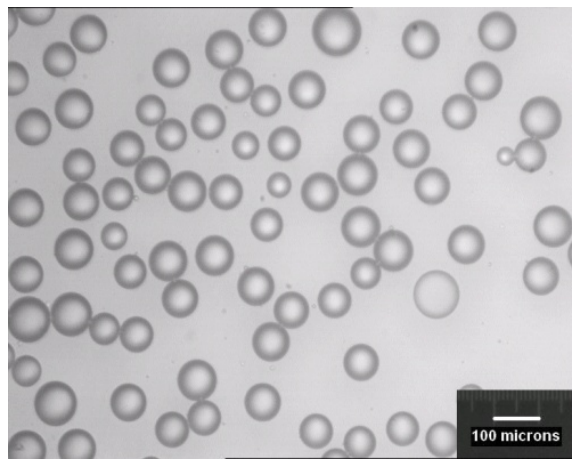

d

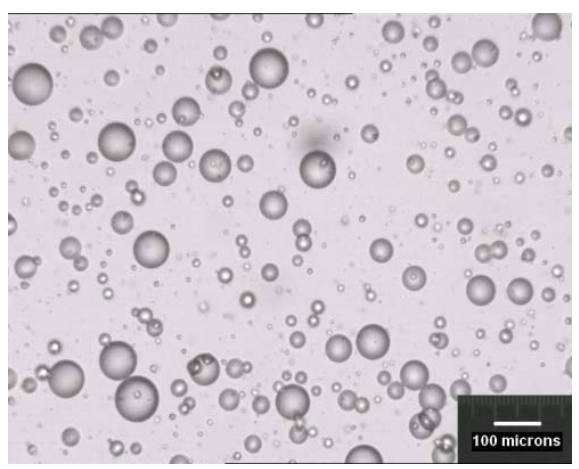

Figure 5 w/o emulsion droplets produced in continuous phases with sunflower oil contents of (a) $0 \%$ (b) $40 \%$ (c) $60 \%$ and (d) $80 \%$ at a $70 \mathrm{l} \mathrm{m}^{-2} \mathrm{~h}^{-1}$ injection rate and shear stresses of 70, 126, 127 and 120 dynes $\mathrm{cm}^{-2}$ respectively 


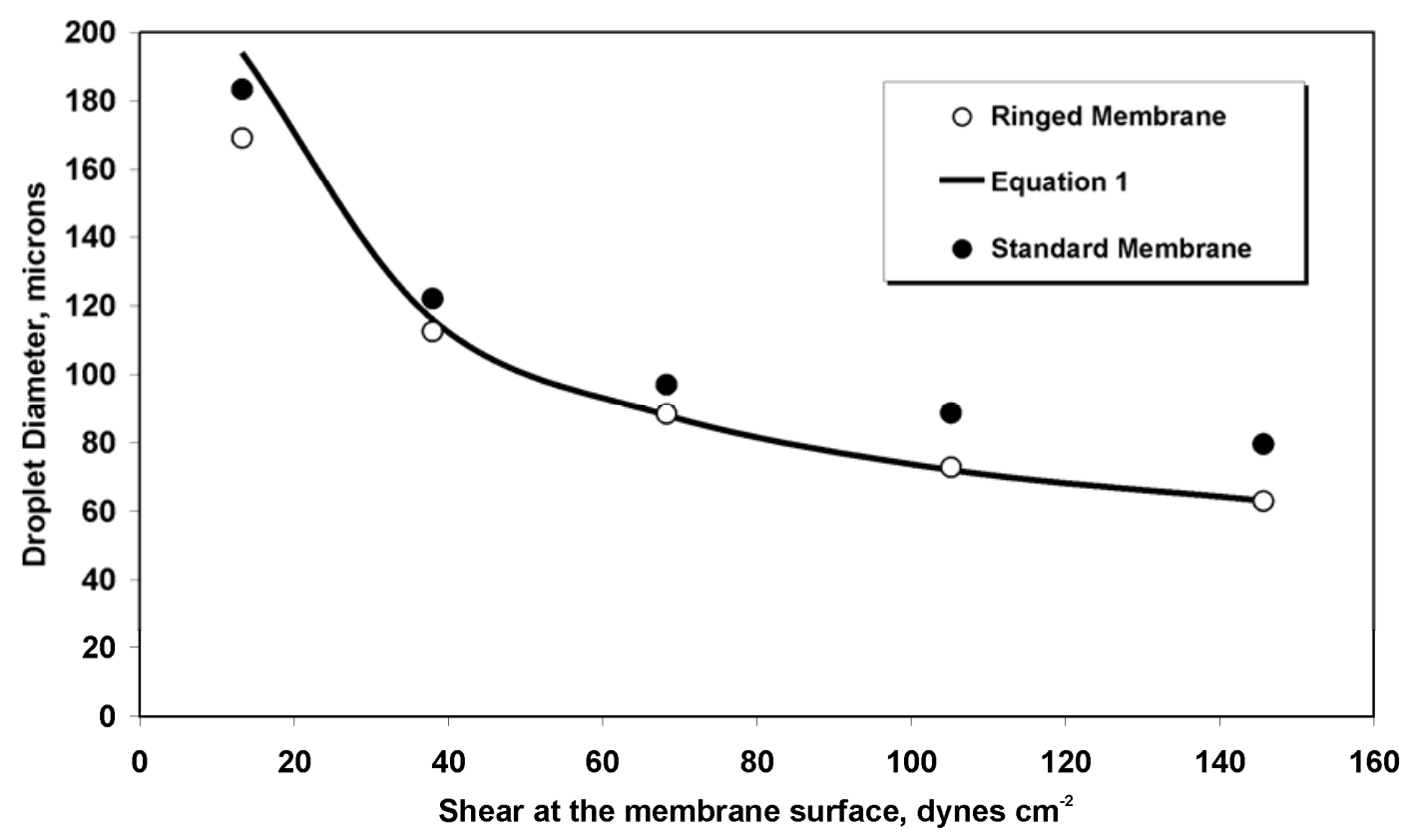

Figure 6 Comparison of $\mathrm{o} / \mathrm{w}$ emulsion data produced using the ringed membrane and the standard membrane with a continuous phase viscosity of $1 \mathrm{cP}$ including predicted values from equation 1 


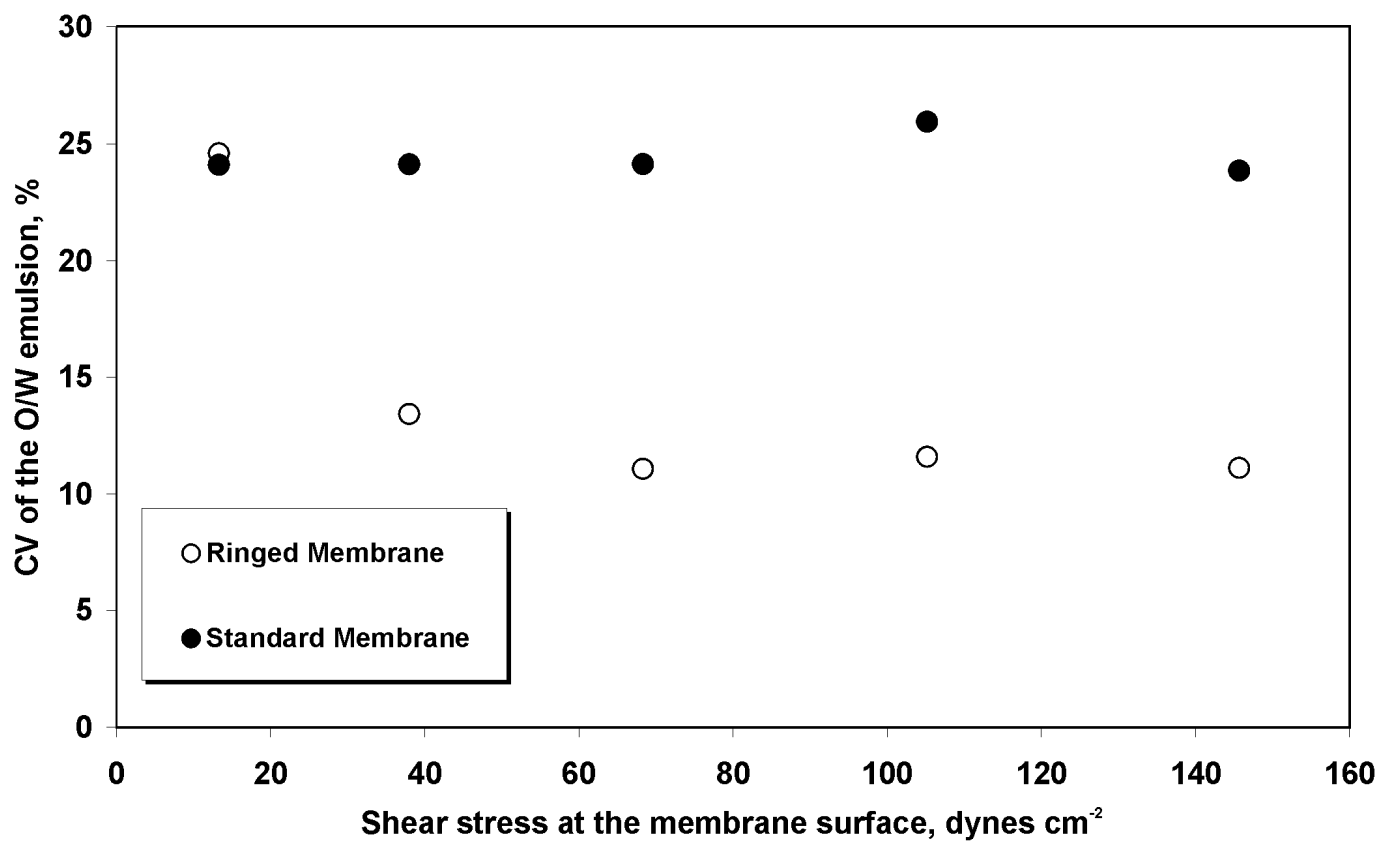

Figure 7 Comparison of CV values from o/w emulsion data produced using the ringed membrane and the standard membrane with a continuous phase viscosity of $1 \mathrm{cP}$ 
13 dynes $/ \mathrm{cm}^{2}$

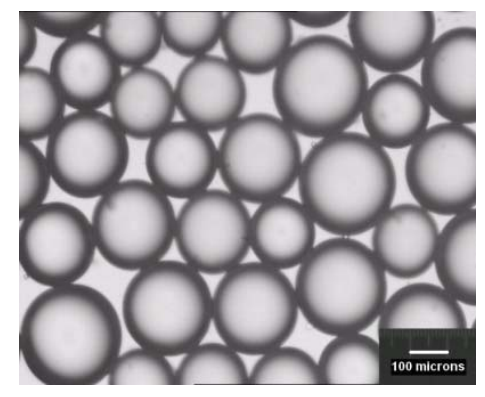

105 dynes $/ \mathrm{cm}^{2}$

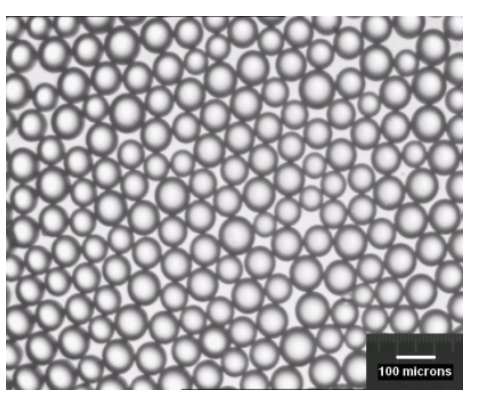

38 dynes $/ \mathrm{cm}^{2}$

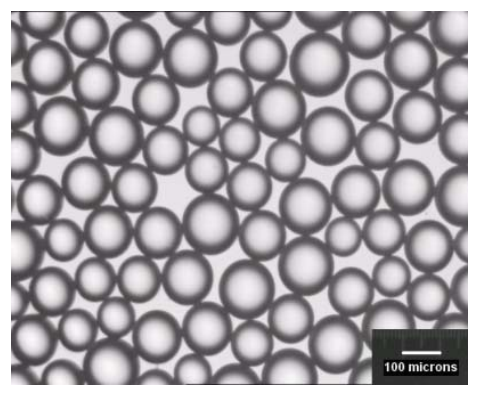

146 dynes $/ \mathrm{cm}^{2}$

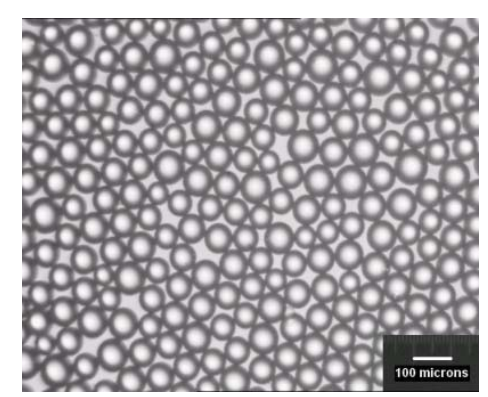

Figure 8

o/w emulsion images for the ringed membrane at an injection rate of

$168 \mathrm{l} \mathrm{m}^{-2} \mathrm{~h}^{-1}$ and a $0 \%$ continuous phase CMC content at different membrane shear stresses 


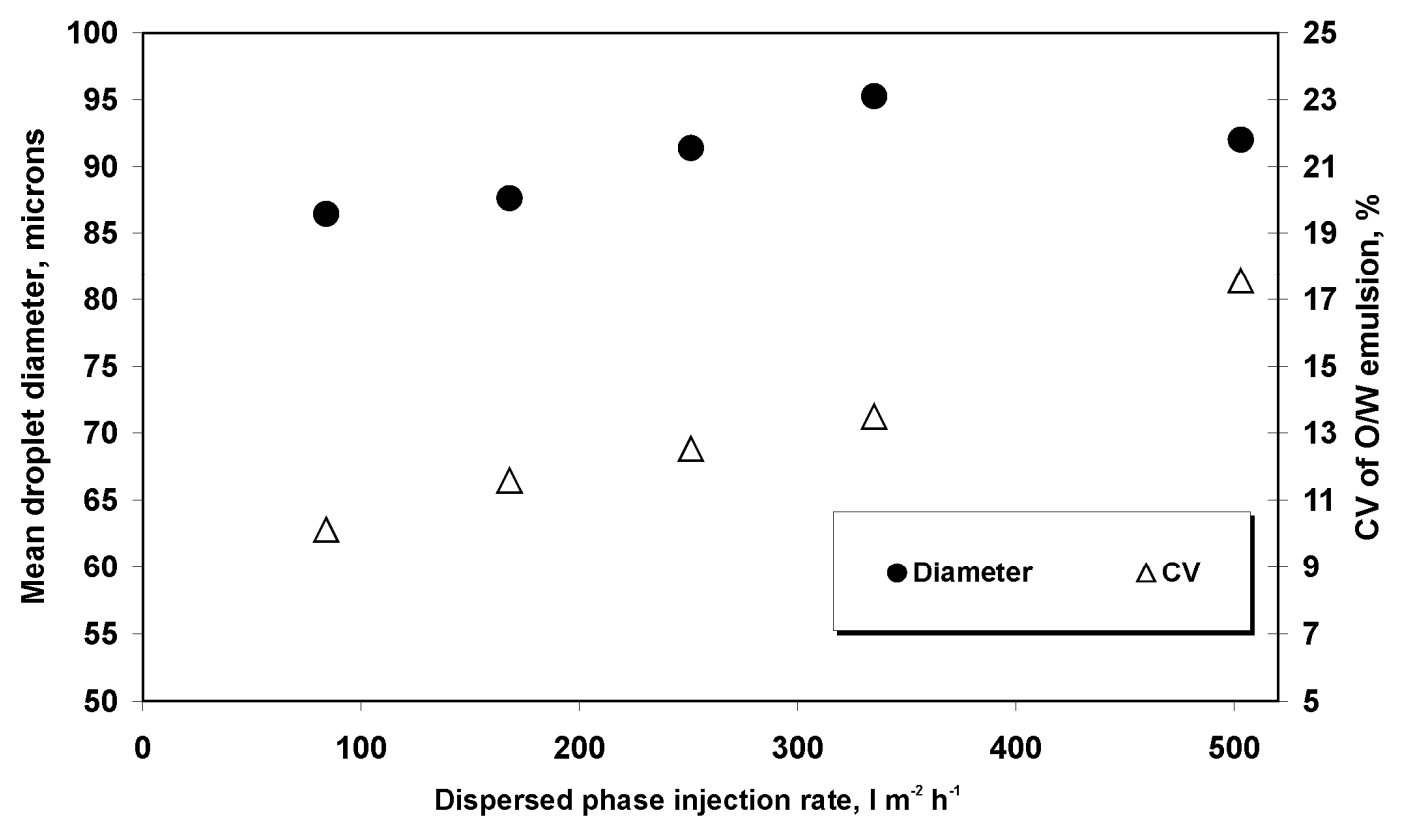

Figure 9 Droplet diameter and CV variation for the O/W emulsion as a function of dispersed phase injection rate: $0 \%$ CMC content and a shear rate of 68 dynes $\mathrm{cm}^{-2}$ 


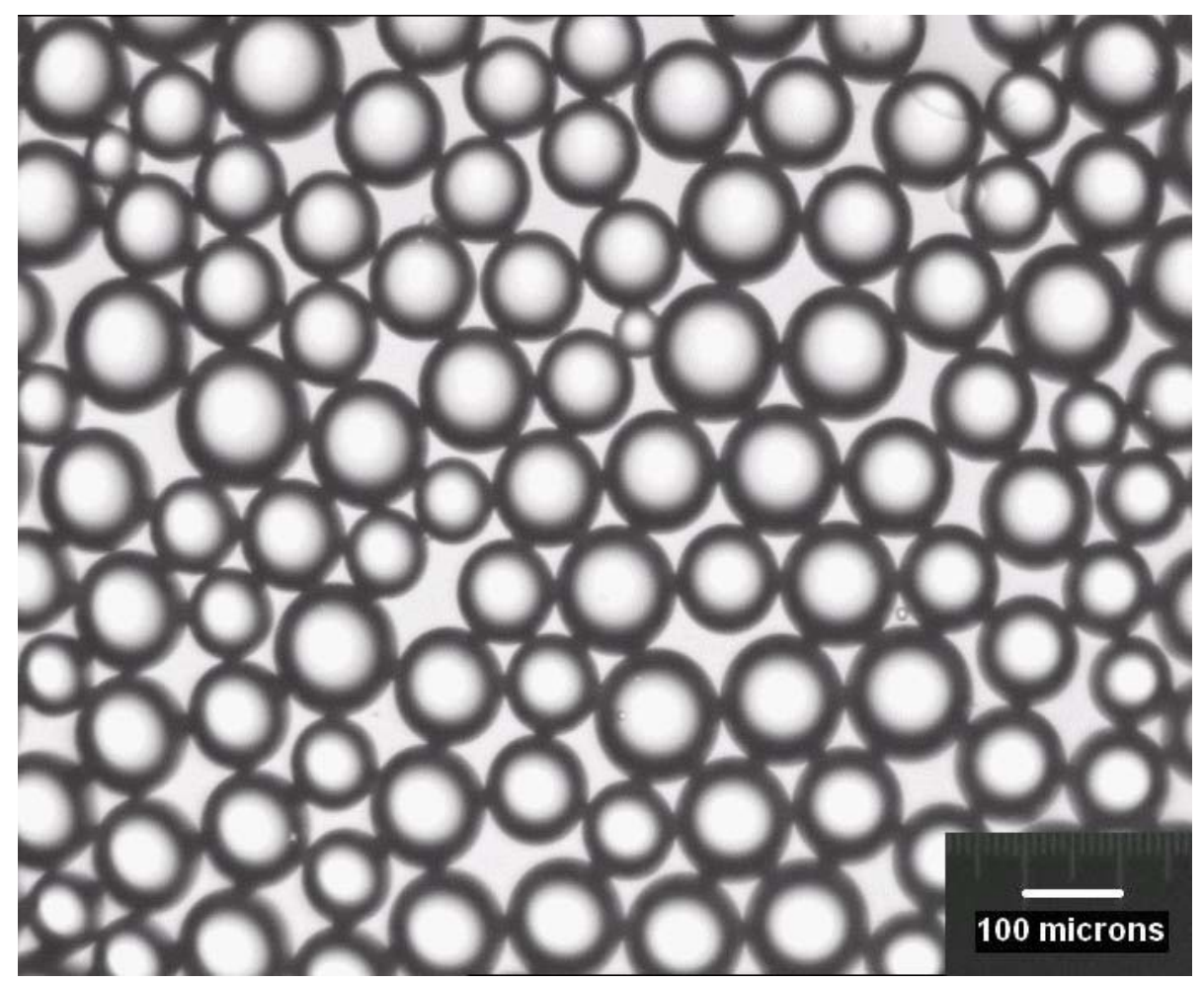

Figure 10 Image of o/w emulsion image for the ringed membrane at an injection rate of $503 \mathrm{l} \mathrm{m}^{-2} \mathrm{~h}^{-1}$ and a $0 \%$ continuous phase CMC content at a membrane shear stress of 68 dynes $\mathrm{cm}^{-2}$ 


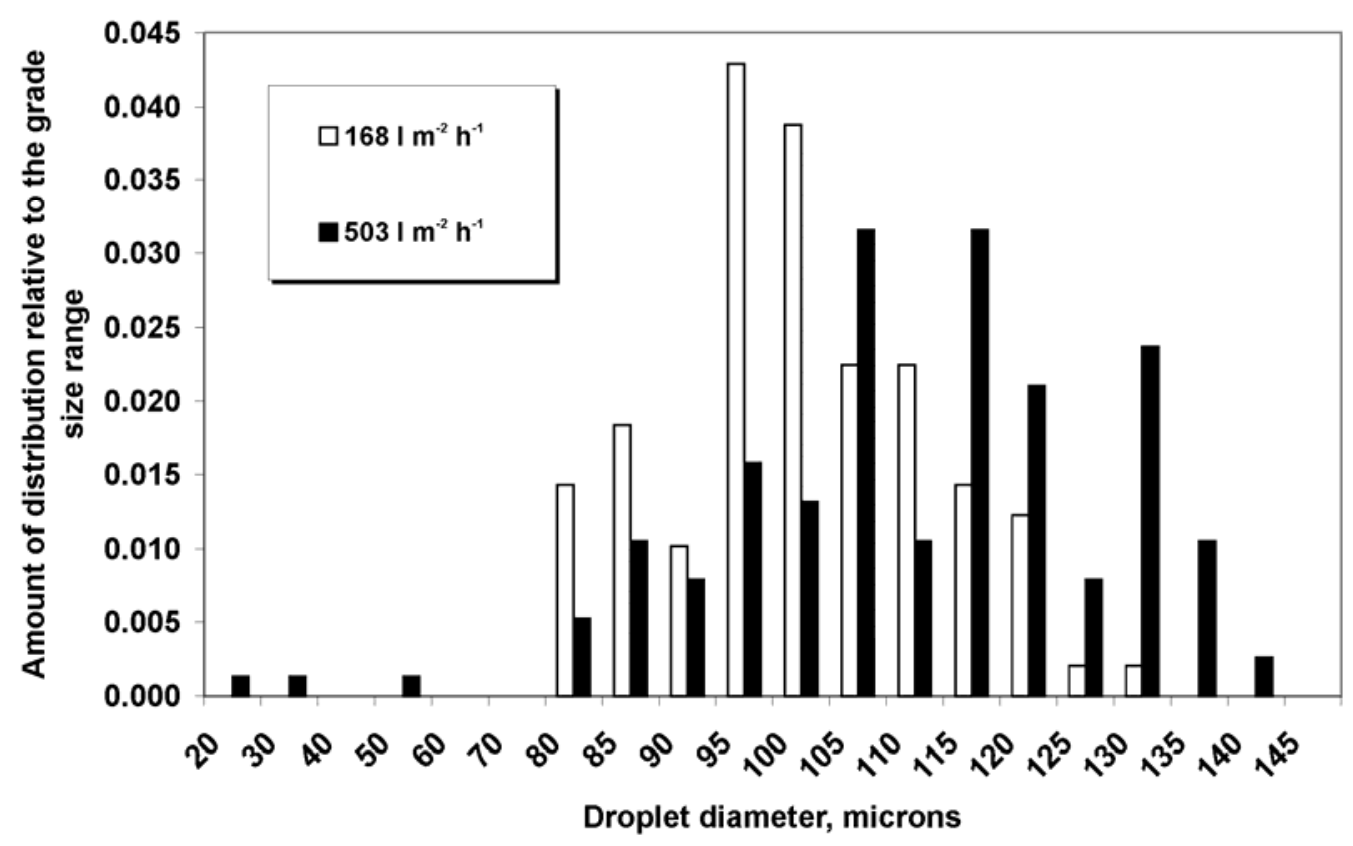

Figure 11 ImageJ analysis of images at 168 and $503 \mathrm{l} \mathrm{m}^{-2} \mathrm{~h}^{-1}$ dispersed phase injection rate at $0 \%$ continuous phase CMC content at a membrane shear stress of 68 dynes $\mathrm{cm}^{-2}$ 


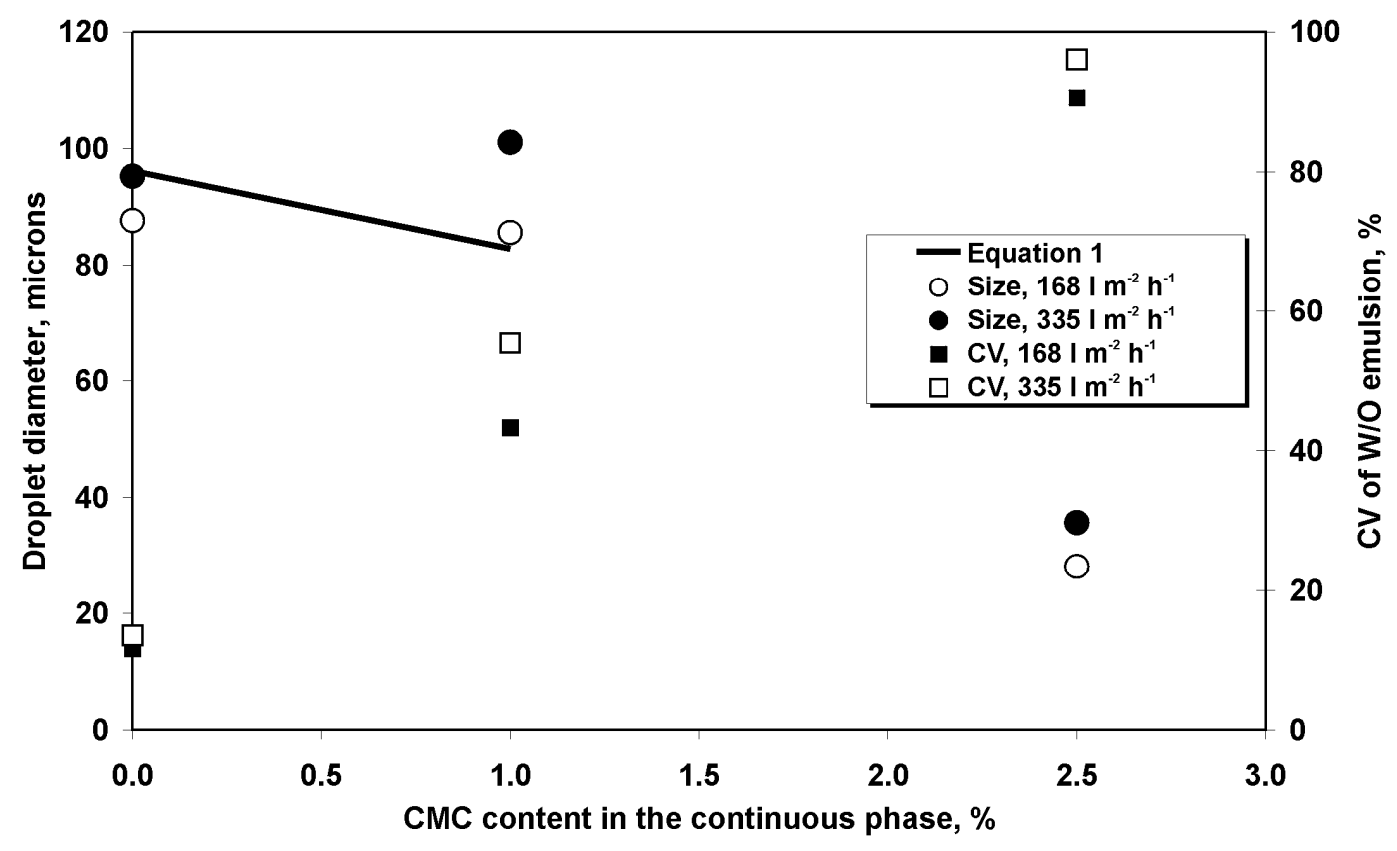

Figure 12 Comparison of predicted droplet diameter and the measured mean droplet diameter for the o/w emulsion at 168 and $335 \mathrm{l} \mathrm{m}^{-2} \mathrm{~h}^{-1}$ injection rate at the radial position of the ring under a constant shear stresses of 78.0 and 7.0 dynes $\mathrm{cm}^{-2}$ for $1 \%$ and $2.5 \%$ CMC content in the continuous phase 